Published in: Marine Environmental Research 114: 58-64 (2016).

DOI: 10.1016/j.marenvres.2015.12.013

(C) Elsevier Ltd. All rights reserved

\title{
The flip-or-flop boutique: Marine debris on the shores of St Brandon's Rock, an isolated tropical atoll in the Indian Ocean
}

Hindrik Bouwman ${ }^{a, *}$, Steven W. Evans ${ }^{a, b}, N^{2}$ Cole $^{c, d}$, Nee Sun Choong Kwet Yive ${ }^{e}$, Henrik Kylin ${ }^{a, f}$

${ }^{a}$ Research Unit: Environmental Sciences and Management, North-West University, Potchefstroom, South Africa

bSARCHI Chair on Biodiversity Value and Change, School of Mathematics and Natural Sciences, University of Venda, Thohoyandou, South Africa

'Durrell Wildlife Conservation Trust, Les Augrès Manor, Trinity, Jersey Channel Islands

${ }^{\mathrm{d}}$ Mauritian Wildlife Foundation, Grannum Road, Vacoas, Mauritius

eDepartment of Chemistry, University of Mauritius, Mauritius

fDepartment of Thematic Studies - Environmental Change, Linköping University, Linköping, Sweden;

*Corresponding author at:

Henk Bouwman

School of Environmental Sciences and Planning

North-West University

P. Bag X6001

Potchefstroom 2520

South Africa

Tel: +27 182992377

Fax: +27 182992503

henk.bouwman@nwu.ac.za

Highlights

- Marine debris was studied on 15 islets of St. Brandon's Rock, Indian Ocean

- Plastics made up $79 \%$ of 50000 debris items at 0.74 items $\mathrm{m}^{-1}$ shore length

- Origin of the items is most likely Southeast Asia and the Indian subcontinent

- Islets differed in the composition of debris types

- Compact fluorescent lights suggest facilitated long-range transport of mercury

- Coral islands may re-concentrate pollutants associated with debris 


\section{ABSTRACT}

Isolated coral atolls are not immune from marine debris accumulation. We identified Southeast Asia, the Indian sub-continent, and the countries on the Arabian Sea as most probable source areas of 50000 items on the shores of St. Brandon's Rock (SBR), Indian Ocean. 79\% of the debris was plastics. Flip-flops, energy drink bottles, and compact fluorescent lights (CFLs) were notable item types. The density of debris ( $0.74 \mathrm{~m}^{-1}$ shore length) is comparable to similar islands but less than mainland sites. Intact CFLs suggests product-facilitated long-range transport of mercury. We suspect that aggregated marine debris, scavenged by the islands from currents and gyres, could re-concentrate pollutants. SBR islets accumulated debris types in different proportions suggesting that many factors act variably on different debris types. Regular cleaning of selected islets will take care of most of the accumulated debris and may improve the ecology and tourism potential. However, arrangements and logistics require more study.

Keywords:

Plastic

Polyurethane foam

Mercury

Management

Wreck

Compact fluorescent light 


\section{Introduction}

The amount of waste entering the oceans on a yearly basis is immense. For example, in 2010 an estimated 4.8-12.7 million metric tons (MMT) of plastic waste entered the world's oceans (Jambeck et al., 2015). The impact of marine debris and microplastics $(<5 \mathrm{~mm})$ in particular remains subject to investigation but there are indications of negative effects on biota, mediated by both the physical and chemical characteristics and composition of plastics and microplastics (e.g. Barnes et al., 2009; Watts et al., 2014; Cole et al., 2015; Hardesty et al., 2015). The potential of impacts of marine plastic debris on human health is also attracting attention (Seltenrich, 2015).

Of the top 20 countries releasing waste into the oceans, 10 have shores on the Indian Ocean, the third largest ocean in the world. Combined, these 10 released an estimated 1.73-4.61 MMT of waste in 2010, and an increasing trend is expected (Jambeck et al., 2015). A few studies have reported on marine debris in the Indian Ocean (Barnes, 2004; Eriksen et al., 2014; Hoarau et al., 2014; Lavers et al., 2013; Ryan, 2008, 2013; Ryan et al., 2012; Sigler, 2014). There were also studies from the associated Red Sea (Abu-Hilal and Al-Najjar, 2004), the Gulf of Oman (Claereboudt, 2004), the Java Strait (Willoughby et al., 1997), and the Malacca Strait (Khairunnisa et al., 2012). Madzena and Lasiak (1997) on the Transkei coast of South Africa, Jayasiri et al. (2013) for beaches near Mumbai, Nel and Froneman, (2015) on the south east coast of South Africa, and Duhec et al. (2015) from Seychelles published the only studies we could find that quantified beached debris in the Indian Ocean proper.

The spatial distribution of beached and sunken debris is not homogenous. Factors such as size, shape, density, distance from source, dispersion from release, re-concentration in gyres, time spent at sea, encrustation, formation of biofilm, effects of wind and waves, retention ability of the beaches, separation on the beaches by wind and waves, currents, and physiography, etc. all play a role from global to very small scales (e.g. Abu-Hilal and Al-Najjar, 2004; Browne et al., 2010; Cunningham and Wilson, Duhec et al., 2015; 2003; Goldstein et al., 2013; Isobe et al., 2014; Lebreton et al., 2012; Leite et al., 2014; Poeta et al., 2014; Ryan, 2013; Titmus and Hyrenbach, 2011; Turra et al., 2014). These influences may affect debris deposition even at remote beaches, and therefore also on their management.

Globally, marine debris on coral reefs and islands has received attention (e.g. Duhec et al. 2015; Ebbesmeyer et al., 2012; Kwon et al., 2014; Miao et al., 2000; Richards and Beger, 2011). We report the number, composition, differential distribution, implications, and management options of marine debris on the shores of the islets of St. Brandon's Rock, an isolated coral reef atoll located 400 $\mathrm{km}$ north of Mauritius and $1000 \mathrm{~km}$ east of Madagascar in the Indian Ocean (Figure 1).

\section{Materials and methods}

St Brandon's Rock (SBR; $-16^{\circ} 23^{\prime} \mathrm{S}, 59^{\circ} 27^{\prime} \mathrm{E}$ ) belongs to the Republic of Mauritius, and is also known as Saint Brandon's, St Brandon's Island, St Brandon's Atoll, or Cargados Carajos (Figure 1). This isolated atoll is about $56 \mathrm{~km}$ long and $22 \mathrm{~km}$ wide with a north-south orientation. Its coral reef and lagoon system consists of 15 prominent sandbars and 24 vegetated islets (Figure 1; Government of Mauritius 1986, Post et al. 1998). Currents and wind are mainly from the east (J. Merven pers. comm.). Low impact fishing and some tourism are the only economic activities on SBR, but commercial fishing does occur further out from the atoll. There were 48 people (no women or children) temporary stationed on SBR in 2010, and 41 (one women and no children) in 2014, consisting of fishermen and 
staff of the National Coast Guard and Mauritius Meteorological Services. Few pleasure craft visit SBR, estimated at five per year up to 2010 (J. Merven pers. comm.).

We visited SBR on 25-30 October, 2010. Transport was with the fishing vessel La Derive (Raphaël Fishing Co. Ltd.). Due to sea state and time constraints, we restricted surveys to 15 islets and sandbars; none were inhabited. Supporting observations from an expedition in October 2014 have been added here. The shore surveys were conducted based on UNEP (Cheshire et al., 2009) protocols. We conducted beach transects of varying lengths on the shores of the islets (Table 1), recording GPS coordinates for the start and end points. We recorded and classified all debris items larger than $5 \mathrm{~mm}$ between the water and the strandline. Items on which the labelling was still legible were inspected and photographed to obtain product information. After return from the expedition, Google was used as search engine to obtain origin of manufacture. The counts were converted to items per metre shore length, and then multiplied with the shore length of each island. The convoluted nature of the shores and large differences in distance between strandline to water's edge prevented calculation of the density as items per surface area, a common metric to express abundance of debris on shores. The means of the items per metre for the 15 islets were then used to extrapolate to the shore length of all islets combined. The shore lengths were obtained using GIS (Mapviewer 7.6).

We conducted seven scuba dives in October 2014 to survey corals, sea cucumbers, and fish on SBR. On three of these dives, six $50 \mathrm{~m}$ by $10 \mathrm{~m}$ wide transects were completed to survey sunken debris. On all other dives, the dive team members were instructed to report any sunken debris. The dive teams consisted of between four and six divers, four of them participated in all dives. The dives were done at different locations in the southern half of the lagoon. Combined dive time for all dives was 26.8 hours. At a site with a recent shipwreck located in a shallow lagoon, snorkelling was done around the site up to $20 \mathrm{~m}$ away from the wreck. Debris were noted but not counted.

Since each islet was different in shape, location, orientation, and width of shore, comparative bivariate statistics was not deemed appropriate. Non-metric multidimensional scaling (NMS) was used to investigate differences in compositional patterns of debris types between islets (using PC-ORD 6.2, MjM Software design). The data was relativized per islet for debris types. The distance measure was Sørensen. Four axes were allowed with 200 iterations, random starting conditions, and 50 runs of real and randomised data to determine dimensionality.

\section{Results}

We counted 28948 items on the 15 islets (Table 1) over $38 \mathrm{~km}$ of shore length. Extrapolation to the entire shore length of SBR $(66 \mathrm{~km})$ predicted more than 50000 items at a mean density of 0.76 items per metre shore length. Items ranged from very large $(>1 \mathrm{~m})$ to $5 \mathrm{~mm}$, the smallest size that we counted. Plastic items (from bottle caps to car seats and helmets) composed $54 \%$ of the items found, and flip-flops (a foamed plastic) contributed a further $23 \%$ (Fig. 1). Together with polyurethane foam and polystyrene, plastics of all types combined represented $79 \%$ of the debris. Product labels on the items and using Google to trace manufacturing origin of brand names revealed a preponderance of countries such a Malaysia, Sri-Lanka, Thailand, Indonesia, India, and China. Only a few European brand names were encountered, often luxury food packaging. Seven such items were encountered on île Tortue, all in a black plastic refuse bag.

We did not encounter any sunken debris on any of the scuba dives. The only sunken debris encountered was during snorkelling around the wreckage of the fishing vessel that stranded in 2010 (after we left). There were items such as keys, a cellular phone, chains, ropes, cables, and bulkheads 
in a radius of $20 \mathrm{~m}$ around the wreckage. None of these submerged items resembled the onshore debris we encountered in 2010. Most of the floatable items have probably already been removed by wave action during storms.

On the beaches, we noticed three item types that may be of importance. The first was the flipflop - a vast number (11500) was estimated for SBR. The flip-flops were of all sizes, many of them child sizes and many also clearly meant for women. The second item type was the glass bottles of the Krating Daeng energy drink that inspired Red Bull, the well-known energy drink sold globally. Krating Daeng in glass bottles is produced in Thailand and Indonesia and sold in Southeast Asia. The bottle and metal cap features two fighting wild gaurs (which is also the basis for the Red Bull logo) that makes it very recognisable. The third item type of note was compact fluorescent lights (CFLs), many of which were seen on the beaches or even buried in the sand, often intact. Unfortunately, when we started out, we did not classify CFLs separately from incandescent light bulbs in the "light bulb" category.

The NMS ordination derived three axes. Axis 1 explained $74.3 \%$ of the correlation between the ordination distances, axis 2 explained $6.7 \%$ and axis 3, 15.7\%. Axes 1 and 3 contributed the most and are illustrated (Fig. 2). The final stress (according to Kruskal's stress formula, rescaled to between 0 and 100; McCune and Grace 2002) was 4.89 (which is considered 'very good'; McCune and Grace, 2002) with an instability of 0.0000 (no further improvement possible), reached after 73 iterations. A convex hull was drawn encompassing all lagoon islets. Albatross and Sirène, the two outer islets, ordinated outside the convex hull. The debris class vectors pointed in different directions. The foam and plastics vectors were oriented opposite to flip-flops and polystyrene. Rope and metal vectors were oriented in the second dimension, perpendicular to most other vectors.

\section{Discussion}

\subsection{Debris composition and possible sources}

The composition of the debris, particularly children's and women's flip-flops (23\% of the total; Table 1), and the lack of any benthic debris observed in the lagoon during snorkelling and scuba diving, makes it unlikely that local sources from the few fishermen and tourists would have contributed significantly. Lagoons associated with populated centres can have benthic debris pollution as high as 234 items $\mathrm{km}^{2}$ (Richards and Beger, 2011). Shoe apparel made up $13.4 \%$ of the beached debris on beaches in the Java Sea near Jakarta (Willoughby et al., 1997), near $0.4 \%$ of floating debris in the Strait of Malacca and the Bay of Bengal (Ryan, 2013), and 11\% on Alphonse, $1290 \mathrm{~km}$ north-west of SBR.

There was a lack of characteristic brand names from Mauritius on any debris, the closest major populated centre. Together with the Krating Daeng bottles found, it is likely that most items arrived from Southeast Asia, the Indian sub-continent, and the countries on the Arabian Sea. The route the items took is possibly regulated by the Northern Equatorial Current and the North Equatorial Counter Current system that flows past these regions (Maximenko et al., 2012 from work based on Lagrangian drifters), and with its southern (westwards) component reaching SBR. Krating Deang bottles were also found at Alphonse Island, making up $74 \%$ of the glass energy dinks bottles found there (Duhec et al., 2015). It should be stressed that geographical source attribution of marine debris is very difficult. Place of manufacture need not be the same as the eventual place of release into the ocean.

The only local source may have been debris from wrecks on the reef. There is about one wreck every two years on SBR (J. Merven pers. comm.). A foreign-flagged fishing vessel stranded in 2010, and a yacht participating in the Volvo Ocean race ran aground in 2014 not far from the fishing vessel. The yacht has since been removed but a close inspection of the fishing vessel in 2014 showed that the 
double hull was filled with injected polyurethane foam. Constant currents, wave action, and grinding of similar wrecks on coral probably release many small and large pieces of foam and complete blocks. One such block was found in 2010 without its source being recognised the time.

The luxury food packaging of European origin (Dutch and German) are probably from yachts visiting or passing the islands. Foreign yachts and pleasure craft (mainly for sport fishing) have to clear customs in Mauritius first before visiting SBR, while Mauritian yachts may visit unrestricted. These vessels normally anchor near Île du Sud, where the St. Raphaël Fishing Co. takes care of waste.

Fishing gear such as floats, rope, and stranded ghost nets were also encountered (as on Alphonse Island., 2015), suggesting, like elsewhere in the world, that ship-based sources also contributes to the problems here. However, as elsewhere in the Indian Ocean, the major source of marine debris on SBR is likely to be distant land-based (80\% according to Jambeck et al., 2015).

The debris density on SBR's shores corresponds with a number of other studies that investigated remote islands (Benton, 1995; Morishige et al., 2007; Ribic et al., 2012a; Ribic et al., 2012b; see also Table 2). One regionally comparable study (Willoughby et al., 1997) conducted in the Java Sea correlated item density with distance from Jakarta, Indonesia. Using the item density observed for SBR $\left(0.76 \mathrm{~m}^{-1}\right.$ shoreline) the relationship that Willoughby et al. (1997) present, predict that SBR would be between 7 and $10 \mathrm{~km}$ from the source of the debris. However, SBR is $3350 \mathrm{~km}$ from the nearest potential source of the majority of the items we found, demonstrating the sink effect of small isolated island atolls in trapping and accumulating marine debris.

Comparisons with other studies show that SBR had comparable debris loadings (Table 2). Of the islands with none to few inhabitants, SBR marine debris density falls somewhere in the middle, and mainly lower than islands with many inhabitants, and generally much less compared with mainland sites. One should keep in mind that beach counts might not represent the entirety of island loadings. Beach loadings are easy and mostly pleasant to measure (especially on SBR), while rocky shores and mangrove coasts present many obstacles.

Alphonse Island has a shoreline of $5.5 \mathrm{~km}$, a landing strip, and a population that can exceed 50 in the monsoon season (Duhec et al., 2015). The composition of the debris resembled that of SBR to some extent, but there were differences. At SBR, 79\% of the items were plastic, contrasting somewhat with $96 \%$ at Alphonse Island. Flip-flops made up $23 \%$ of the items on SBR's beaches, while it was less than $9 \%$ at Alphonse Island. Polystyrene made up about $7 \%$ of the items at Alphonse Island, but only $0.6 \%$ at SBR (Duhec et al., 2015). Although the other categories differed between the two studies, it is apparent that there are differences in debris between the two islands, both in shore density and in composition. The source areas though may correspond, given the apparent similarity between the item types.

We did not count debris smaller than $5 \mathrm{~mm}$. Other studies suggest that this range of debris can make up a substantial amount on shores (Browne et al., 2011; Cole et al., 2011; Liebezeit and Dubaish, 2012; Hidalgo-Ruz and Thiel, 2013; Jambeck et al., 2015). Further investigation on the quantity of smaller items is therefore warranted.

\subsection{Associated pollutants}

It is well known that plastic debris can accumulate chemical pollutants from water and transport these over large distances (e.g. Ogata et al., 2009; Hirai et al., 2011). Since CFLs contain mercury in their switches, marine CFL debris could facilitate long-range transport of mercury. CFL waste is estimated to reach 9300000000 units in 2015, containing $9300 \mathrm{~kg}$ of mercury (Pant and Singh, 2014). If the CFLs can be transported intact over large distances, then mercury will be 
transported with it and released when smashed on coral or shores. During cruises in the Strait of Malacca and the Bay of Bengal, floating CFLs were observed; light bulbs as an inclusive category made up $0.2 \%$ of 18211 items observed (Ryan, 2013). Light tubes made up about $0.5 \%$ of the items on the shores of Alphonse Island (Duhec et al., 2015). Therefore, not only can organic pollutants reach remote areas via debris-facilitated transport, but also the mercury associated with products. How big or small the problem of product-facilitated transport of mercury is remains to be investigated.

Our data suggests the potential of isolated oceanic islands to act as traps or sinks of marine debris; here we term this effect as 'island scavenging'. Morishige et al. (2007) refers to the potential of debris circulating for many years in oceanic gyres and currents to accumulate on islands. Consequently, trapping and locally releasing inherent and accumulated chemicals from debris seems likely. More debris may be scavenged by islands located near gyres or currents than islands located further away. The 'scavenging' effect is likely to be continuous because the gyre-trapped marine debris will have multiple opportunities of being scavenged as the gyre rotates. Such a "re-concentration" of debris-associated pollutants in excess of background levels has a parallel in the well-known global fractionation and condensation of persistent organic pollutants (POPs). This tends to accumulate POPs in the colder regions of the earth due to the chemical and physical nature of the POPs molecules (Scheringer et al., 2000; Wania and Mackay, 1996). Island scavenging can therefore be seen as a reconcentration mechanism independent of cold distillation as the molecules remain associated with debris most of the time, suggesting that tropical regions - especially coral reefs - may also suffer consequences of re-concentrated pollutants in excess of background concentrations.

\subsection{Debris distribution between islets and management}

As mentioned in the introduction, many factors influence the small-scale distribution of debris on shores. If our deduction of distant source areas were correct, then each islet would have a similar debris type composition as each has the same chance to capture the same debris types that comes drifting in. However, we found differential accumulation (Fig. 2). Had all shores had equal proportions of debris types, the islets would have ordinated close together and the item-type vectors would be less prominent (such as for rubber and glass in Table 2) or even absent, but not markedly opposite or perpendicular. We stratified for islet sizes and location (north, central, south) and shore lengths, but no pattern emerged. The best (but not very convincing) stratification came from classifying the islands as lagoon islets or outer islets (Fig. 2). The two outer islets (Albatross and Sirène), as well as La Derive and Digier are characterised by higher proportions of wood, polystyrene, and flip-flops. Baleine, Roseate Island, and Grand Capitaine were characterised by higher proportions of polyurethane foam and plastic, while Loup Garou and Petit Raphael had higher proportions of rope and metal items. Glass and rubber had similar proportions on all islets. We can only conclude that many different factors, such as wind, local currents, beach slopes, and different debris retention ability gives each islet a particular debris composition. We will have to investigate if these patterns persist over time.

Comparisons with Alphonse Island (Duhec et al., 2015) are difficult, as Alphonse Island is a single island with a $5.5 \mathrm{~km}$ shoreline, while SBR is an atoll consisting of numerous islets and sand banks. However, their study focussed on two $500 \mathrm{~m}$ sections on the up-wind side of the island. Judging from their data, the two stretches did differ, consistent with our findings.

It should be kept in mind that SBR, as with many other small atolls, are low in elevation. Frequent storms have the ability to wash completely over the islands, as happened in November 2014. A following visit in November showed an almost complete removal of accumulated debris (J Mervin pers. comm.). 
Combined, the five islets with the highest number of debris combined (ca 23000 ; Table 1) had just under $50 \%$ of the debris. Regular cleaning of these islets, together with the inhabited île du Sud and île Raphael, would take care of most of the debris on SBR. SBR is also the most important breeding site for sea turtles in the Republic of Mauritius. Île Cocos, Puit à Eau, Albatross, Sirène, and Grand Dagorne South are the most important breeding islets in SBR (unpublished data). Cleaning these beaches may therefore have positive effects (Triessnig et al., 2012) not least from a tourism point of view.

The almost non-existent infrastructure however, makes proper waste handling in situ very difficult if not impossible. Burning is an option but not recommended as toxic pollutants such as dioxins and PCBs will be released into an otherwise (almost) pristine ecosystem. Removal by fishing vessels back to Mauritius is not an option; the holds are filled with fish and there are obvious hygiene considerations. Temporary storage in containers and regular removal to Mauritius by small cargo vessels or via frequent trips to the region by the Mauritius National Coast Guard for proper waste handling seems the best (but for the former costly) option. Recruitment studies are needed (Barnes, 2004; Smith and Markic, 2013) to determine the expected waste harvest. This will inform the local storage and loading infrastructure needed, labour requirements, as well as the frequency of removal.

\section{Conclusions}

Isolated coral atolls in the West Indian Ocean, as elsewhere in the world, are not immune from marine debris accumulation. Brand names on debris items suggest Southeast Asia, the Indian subcontinent, and the countries on the Arabian Sea as probable source areas of the items, carried in by the Northern Equatorial Current and North Equatorial Counter Current system. Plastic items made up $79 \%$ of the debris, with flip-flops, energy drink bottles, and CFLs as notable items types. The density of debris ( $0.74 \mathrm{~m}^{-1}$ shore length) is comparable to similar isolated islands, but less than most mainland sites. Micro plastics also needs more attention.

Intact CFLs suggests product-facilitated transport of mercury. We also suspect that aggregated marine debris, scavenged by the islands from currents and gyres, could re-concentrate inherent and accumulated pollutants that may subsequently be released at concentrations higher than background concentrations, an aspect that needs further investigation.

Islets of the SBR atoll collected debris types in different proportions suggesting that many factors act variably on different debris types. Regular cleaning of seven islets will take care of most of the accumulated debris. Additional islets can be targeted for cleaning to protect sea turtles. However, arrangements and logistics require more study.

\section{Acknowledgements}

We thank the Raphaël Fishing Company, in particular Alain Langlois, the crew of La Derive, Didier Bétuel, Gabriel Begue, and Noel Mourra. Julian Merven provided valuable additional information. Permission to visit the atoll was granted by the Outer Islands Development Corporation, Republic of Mauritius. Funding was provided by the South African Regional Cooperation Fund for Scientific Research and Technological Development administered by the South African National Research Foundation. Opinions expressed and conclusions arrived at are those of the authors, and are not necessarily to be attributed to the NRF. 


\section{References}

Abu-Hilal, A.H., Al-Najjar, T., 2004. Litter pollution on the Jordanian shores of the Gulf of Aqaba (Red Sea). Mar. Environ. Res. 58, 39-63.

Abu-Hilal, A.H., Al-Najjar, T.H., 2009. Plastic pellets on the beaches of the northern Gulf of Aqaba, Red Sea. Aquat. Ecosyst. Health Manag. 12, 461-470.

Barnes, D., 2004. Natural and plastic flotsam stranding in the Indian Ocean. The effects of human transport on ecosystems: Cars and planes, boats and trains. Davenport, D. \& Davenport, J. (Eds.). Royal Irish Academy, Dublin, 193-205.

Barnes, D.K.A., Galgani, F., Thompson, R.C., Barlaz, M., 2009. Accumulation and fragmentation of plastic debris in global environments. Philos. Trans. R. Soc. B-Biol. Sci. 364, 1985-1998.

Benton, T.G., Spencer,T., 1995. From castaways to throwaways - marine litter in the Pitcairn Islands. Biol. J. Linnean Soc. 56, 415-422.

Browne, M.A., Crump, P., Niven, S.J., Teuten, E., Tonkin, A., Galloway, T., Thompson, R., 2011. Accumulation of microplastic on shorelines woldwide: Sources and sinks. Environ. Sci. Technol. 45, 9175-9179.

Browne, M.A., Galloway, T.S., Thompson, R.C., 2010. Spatial patterns of plastic debris along estuarine shorelines. Environ. Sci. Technol. 44, 3404-3409.

Cheshire, A.C., Adler, E., Barbière, J., Cohen, Y., Evans, S., Jarayabhand, S., Jeftic, L., Jung, R.T., Kinsey, S., Kusui, E.T., Lavine, I., Manyara, P., Oosterbaan, L., Pereira, M.A., Sheavly, S., Tkalin, A., Varadarajan, S., Wenneker, B., Westphalen, G. (2009). UNEP/IOC Guidelines on Survey and Monitoring of Marine Litter. UNEP Regional Seas Reports and Studies, No. 186; IOC Technical Series No. 83.

Claereboudt, M.R., 2004. Shore litter along sandy beaches of the Gulf of Oman. Mar. Pollut. Bull. 49, 770-777.

Cole, M., Lindeque, P., Fileman, E., Halsband, C., Galloway, T.S., 2015. The impact of polystyrene microplastics on feeding, function and fecundity in the marine copepod Calanus helgolandicus. Environ. Sci. Technol. 49, 1130-1137.

Cole, M., Lindeque, P., Halsband, C., Galloway, T.S., 2011. Microplastics as contaminants in the marine environment: A review. Mar. Pollut. Bull. 62, 2588-2597.

Convey, P., Barnes, D.K.A., Morton, A., 2002. Debris accumulation on oceanic island shores of the Scotia Arc, Antarctica. Polar Biol. 25, 612-617.

Corbin, C.J., Singh, J.G., 1993. Marine debris contamination of beaches in St-Lucia and Dominica. Mar. Pollut. Bull. 26, 325-328.

Cunningham, D.J., Wilson, S.P., 2003. Marine debris on beaches of the Greater Sydney Region. J. Coast. Res. 19, 421-430.

Duhec, A.V., Jeanne, R.F., Maximenko, N., Hafner, J., 2015. Composition and potential origin of marine debris stranded in the Western Indian Ocean on remote Alphonse Island, Seychelles. Mar. Pollut. Bull. 96, 76-86.

Ebbesmeyer, C.C., Ingraham, W.J., Jones, J.A., Donohue, M.J., 2012. Marine debris from the Oregon Dungeness crab fishery recovered in the Northwestern Hawaiian Islands: Identification and oceanic drift paths. Mar. Pollut. Bull. 65, 69-75.

Eriksen, M., Lebreton, L.C.M., Carson, H.S., Thiel, M., Moore, C.J., Borerro, J.C., Galgani, F., Ryan, P.G., Reisser, J., 2014. Plastic Pollution in the World's Oceans: More than 5 Trillion Plastic Pieces Weighing over 250,000 Tons Afloat at Sea. PLoS One 9, 15.

Goldstein, M.C., Titmus, A.J., Ford, M., 2013. Scales of Spatial Heterogeneity of Plastic Marine Debris in the Northeast Pacific Ocean. PLoS One 8, 11.Government of Mauritius. 1986. Mauritius Cargados Carajos (St Brandon). 1:60 000 OSD 429P Ordnance Map. Chief Surveyor, Ministry of Housing, Lands and Environment, Port Louis, Mauritius. 
Hardesty, B.D., Holdsworth, D., Revill, A.T., Wilcox, C., 2015. A biochemical approach for identifying plastics exposure in live wildlife. Methods Ecol. Evol. 6, 92-98.

Hidalgo-Ruz, V., Thiel, M., 2013. Distribution and abundance of small plastic debris on beaches in the SE Pacific (Chile): A study supported by a citizen science project. Mar. Environ. Res. 87-88, 12-18.

Hirai, H., Takada, H., Ogata, Y., Yamashita, R., Mizukawa, K., Saha, M., Kwan, C., Moore, C., Gray, H., Laursen, D., Zettler, E.R., Farrington, J.W., Reddy, C.M., Peacock, E.E., Ward, M.W., 2011. Organic micropollutants in marine plastics debris from the open ocean and remote and urban beaches. Mar. Pollut. Bull. 62, 1683-1692.

Hoarau, L., Ainley, L., Jean, C., Ciccione, S., 2014. Ingestion and defecation of marine debris by loggerhead sea turtles, Caretta caretta, from by-catches in the South-West Indian Ocean. Mar. Pollut. Bull. 84, 90-96.

Isobe, A., Kubo, K., Tamura, Y., Kako, S., Nakashima, E., Fujii, N., 2014. Selective transport of microplastics and mesoplastics by drifting in coastal waters. Mar. Pollut. Bull. 89, 324-330.

Jambeck, J.R., Geyer, R., Wilcox, C., Siegler, T.R., Perryman, M., Andrady, A., Narayan, R., Law, K.L., 2015. Plastic waste inputs from land into the ocean. Science 347, 768-771.

Jayasiri, H.B., Purushothaman, C.S., Vennila, A., 2013. Plastic litter accumulation on high-water strandline of urban beaches in Mumbai, India. Environ. Monit. Assess. 185, 7709-7719.

Khairunnisa, A.K., Fauziah, S.H., Agamuthu, P., 2012. Marine debris composition and abundance: A case study of selected beaches in Port Dickson, Malaysia. Aquat. Ecosyst. Health Manag. 15, 279-286.

Kwon, B.G., Saido, K., Koizumi, K., Sato, H., Ogawa, N., Chung, S.Y., Kusui, T., Kodera, Y., Kogure, K., 2014. Regional distribution of styrene analogues generated from polystyrene degradation along the coastlines of the North-East Pacific Ocean and Hawaii. Environ. Pollut. 188, 45-49.

Laglbauer, B.J.L., Franco-Santos, R.M., Andreu-Cazenave, M., Brunelli, L., Papadatou, M., Palatinus, A., Grego, M., Deprez, T., 2014. Macrodebris and microplastics from beaches in Slovenia. Mar. Pollut. Bull. 89, 356-366.

Lavers, J.L., Hodgson, J.C., Clarke, R.H., 2013. Prevalence and composition of marine debris in Brown Booby (Sula leucogaster) nests at Ashmore Reef. Mar. Pollut. Bull. 77, 320-324.

Lebreton, L.C.M., Greer, S.D., Borrero, J.C., 2012. Numerical modelling of floating debris in the world's oceans. Mar. Pollut. Bull. 64, 653-661.

Leite, A.S., Santos, L.L., Costa, Y., Hatje, V., 2014. Influence of proximity to an urban center in the pattern of contamination by marine debris. Mar. Pollut. Bull. 81, 242-247.

Liebezeit, G., Dubaish, F., 2012. Microplastics in beaches of the East Frisian Islands Spiekeroog and Kachelotplate. Bull. Environ. Contam. Toxicol. 89, 213-217.

Madzena, A., Lasiak, T., 1997. Spatial and temporal variations in beach litter on the Transkei coast of South Africa. Mar. Pollut. Bull. 34, 900-907.

Martinez-Ribes, L., Basterretxea, G., Palmer, M., Tintore, J., 2007. Origin and abundance of beach debris in the Balearic Islands. Sci. Mar. 71, 305-314.

Maximenko, N., Hafner, J., Niiler, P., 2012. Pathways of marine debris derived from trajectories of Lagrangian drifters. Mar. Pollut. Bull. 65, 51-62.

McCune, B., Grace, J.B., 2002. Analysis of ecological communities. MjM Software Design, Gleneden Beach, Oregon.

Miao, X.S., Swenson, C., Woodward, L.A., Li, Q.X., 2000. Distribution of polychlorinated biphenyls in marine species from French Frigate Shoals, North Pacific Ocean. Sci. Total Environ. 257, 1728. 
Moore, S.L., Gregorio, D., Carreon, M., Weisberg, S.B., Leecaster, M.K., 2001. Composition and distribution of beach debris in Orange County, California. Mar. Pollut. Bull. 42, 241-245.

Morishige, C., Donohue, M.J., Flint, E., Swenson, C., Woolaway, C., 2007. Factors affecting marine debris deposition at French Frigate Shoals, Northwestern Hawaiian Islands Marine National Monument, 1990-2006. Mar. Pollut. Bull. 54, 1162-1169.

Nel, H.A., Froneman, P.W., 2015. A quantitative analysis of microplastic pollution along the southeastern coastline of South Africa. Mar. Pollut. Bull. 101, 274-279.

Ogata, Y., Takada, H., Mizukawa, K., Hirai, H., Iwasa, S., Endo, S., Mato, Y., Saha, M., Okuda, K., Nakashima, A., Murakami, M., Zurcher, N., Booyatumanondo, R., Zakaria, M.P., Dung, L.Q., Gordon, M., Miguez, C., Suzuki, S., Moore, C., Karapanagioti, H.K., Weerts, S., McClurg, T., Burres, E., Smith, W., Van Velkenburg, M., Lang, J.S., Lang, R.C., Laursen, D., Danner, B., Stewardson, N., Thompson, R.C., 2009. International Pellet Watch: Global monitoring of persistent organic pollutants (POPs) in coastal Waters. 1. Initial phase data on PCBs, DDTs, and HCHs. Mar. Pollut. Bull. 58, 1437-1446.

Otley, H., Ingham, R., 2003. Marine debris surveys at Volunteer Beach, Falkland Islands, during the summer of 2001/02. Mar. Pollut. Bull. 46, 1534-1539.

Pant, D., Singh, P., 2014. Pollution due to hazardous glass waste. Environ. Sci. Pollut. Res. 21, 24142436.

Poeta, G., Battisti, C., Acosta, A.T.R., 2014. Marine litter in Mediterranean sandy littorals: Spatial distribution patterns along central Italy coastal dunes. Mar. Pollut. Bull. 89, 168-173.

Post, Y., Kaly, U., Brown, J., Pillay, R.M., Rumjeet, D., Florens, V. \& Pelicier, D. 1998. Management Plan for St. Brandon. Ministry of Economic Development and Regional Cooperation and Ministry of Cooperatives, Fisheries and Marine Resources. Unpublished report. pp. 60.

Ribic, C.A., Sheavly, S.B., Klavitter, J., 2012a. Baseline for beached marine debris on Sand Island, Midway Atoll. Mar. Pollut. Bull. 64, 1726-1729.

Ribic, C.A., Sheavly, S.B., Rugg, D.J., Erdmann, E.S., 2012b. Trends in marine debris along the U.S. Pacific Coast and Hawai'i 1998-2007. Mar. Pollut. Bull. 64, 994-1004.

Richards, Z.T., Beger, M., 2011. A quantification of the standing stock of macro-debris in Majuro lagoon and its effect on hard coral communities. Mar. Pollut. Bull. 62, 1693-1701.

Ryan, P.G., 2013. A simple technique for counting marine debris at sea reveals steep litter gradients between the Straits of Malacca and the Bay of Bengal. Mar. Pollut. Bull. 69, 128-136.

Ryan, P.G., Bouwman, H., Moloney, C.L., Yuyama, M., Takada, H., 2012. Long-term decreases in persistent organic pollutants in South African coastal waters detected from beached polyethylene pellets. Mar. Pollut. Bull. 64, 2756-2760.

Santos, I.R., Friedrich, A., do Sul, J.A.I., 2009. Marine debris contamination along undeveloped tropical beaches from northeast Brazil. Environ. Monit. Assess. 148, 455-462.

Scheringer, M., Wegmann, F., Fenner, K., Hungerbühler, K., 2000. Investigation of the Cold Condensation of Persistent Organic Pollutants with a Global Multimedia Fate Model. Environ. Sci. Technol. 34, 1842-1850.

Seltenrich, N., 2015. New link in the food chain? Marine plastic pollution and seafood safety. Environ. Health Perspect. 123, A34.

Sigler, M., 2014. The effects of plastic pollution on aquatic wildlife: Current situations and future solutions. Water Air Soil Pollut. 225, 9.

Smith, S.D.A., Markic, A., 2013. Estimates of marine debris accumulation on beaches are strongly affected by the temporal scale of sampling. PLoS One 8, e83694.

Thiel, M., Hinojosa, I.A., Miranda, L., Pantoja, J.F., Rivadeneira, M.M., Vasquez, N., 2013. Anthropogenic marine debris in the coastal environment: A multi-year comparison between coastal waters and local shores. Mar. Pollut. Bull. 71, 307-316. 
Titmus, A.J., Hyrenbach, K.D., 2011. Habitat associations of floating debris and marine birds in the North East Pacific Ocean at coarse and meso spatial scales. Mar. Pollut. Bull. 62, 2496-2506.

Topcu, E.N., Tonay, A.M., Dede, A., Ozturk, A.A., Ozturk, B., 2013. Origin and abundance of marine litter along sandy beaches of the Turkish Western Black Sea Coast. Mar. Environ. Res. 85, 2128.

Triessnig, P., Roetzer, A., Stachowitsch, M., 2012. Beach condition and marine debris: New hurdles for sea turtle hatchling survival. Chelonian Conserv. Biol. 11, 68-77.

Turra, A., Manzano, A.B., Dias, R.J.S., Mahiques, M.M., Barbosa, L., Balthazar-Silva, D., Moreira, F.T., 2014. Three-dimensional distribution of plastic pellets in sandy beaches: shifting paradigms. Sci. Rep. $4,7$.

Wania, F., Mackay, D., 1996. Peer reviewed: tracking the distribution of persistent organic pollutants. Environ. Sci. Technol. 30, 390A-396A.

Watts, A.J.R., Lewis, C., Goodhead, R.M., Beckett, S.J., Moger, J., Tyler, C.R., Galloway, T.S., 2014. Uptake and retention of microplastics by the Shore Crab Carcinus maenas. Environ. Sci. Technol. 48, 8823-8830.

Widmer, W.M., Hennemann, M.C., 2010. Marine Debris in the Island of Santa Catarina, South Brazil: Spatial Patterns, Composition, and Biological Aspects. J. Coast. Res. 26, 993-1000.

Willoughby, N.G., Sangkoyo, H., Lakaseru, B.O., 1997. Beach litter: an increasing and changing problem for Indonesia. Mar. Pollut. Bull. 34, 469-478. 


\section{Legends}

Fig. 1. Map and location of St. Brandon's Rock, as well as the proportional composition of debris types. The site of the 2010 shipwreck is indicated with a cross.

Fig. 2. Non-metric multidimensional scaling of the debris type compositions of the different islands. The convex hull encompasses the lagoon islands.

\section{Table 1}

Marine debris composition for 15 islets of St. Brandon's Rock as on October 2010.

\section{Table 2}

Comparable data of stranded marine debris from other regions and sites. 